\title{
Aprender como ensinar física através do livro texto de ciclo básico universitário: um fenômeno didático em questão
}

Learning how to teach physics through the text book of basic university level: a didactic phenomenon in question

Sérgio Choiti Yamazaki ${ }^{1}$ José André Peres Angotti ${ }^{2}$

Demétrio Delizoicov ${ }^{3}$

\section{Resumo}

Este artigo apresenta os resultados de uma tese de doutorado que procurou investigar correlações entre a estrutura de um livro texto (manual) de Física do Ciclo Básico Universitário e certas concepções e ações docentes divulgadas há algumas décadas sobre o ensino de Física. O manual analisado é, segundo nosso levantamento, a obra mais citada em Projetos Político-Pedagógicos de cursos de Física. As análises foram sustentadas em conceitos da Teoria Antropológica do Didático (TAD). Os resultados apontam para uma interpretação segundo a qual há uma congruência entre a forma com que os conteúdos são apresentados nos livros e as noções espontâneas dos professores.

Palavras chave: didática da física; manual de física; fenômeno didático

\section{Abstract}

This paper presents the results of a doctoral thesis that sought to investigated correlations between the structure of a Basic Cycle University Physics textbook and certain conceptions and actions of teachers being released a few decades on the teaching of physics. According to our survey, the analysis manual is the work most frequently cited in political-pedagogical projects in physics courses. Analyses were sustained on concepts of Anthropological Theory of Didactic (TAD). The results point to a congruence between the structure of presentation of content in textbooks and spontaneous notions of teachers.

Keywords: didactics of physics; manual of physics; didactic phenomenon 


\section{Introdução}

Apesar das extensas críticas feitas pelos pesquisadores ao ensino de viés tradicional e de sugestões de inovações para sala de aula, investigações no campo da educação cientifica, desde algumas décadas, têm indicado que professores de distintos níveis educacionais trazem para sala de aula pressupostos didático-pedagógicos e epistemológicos caracterizados por pensamentos e práticas já superadas pela área (CHINELLI, FERREIRA e AGUIAR, 2010). A Física, por exemplo, integrante do currículo escolar no Brasil, conserva há algumas décadas características normalmente atribuídas à metodologia de ensino tradicional (MENEZES e VAZ, 2009). Este cenário sugere a procura de razões que levam à permanência de tais conjecturas, de obstáculos e resistências a transformações didático-pedagógicas nas instituições de Educação Básica - EB - e universitárias dos primeiros ciclos. Para Mion, Angotti e Miquelin (2004), há mesmo um grande "gap de energia" que impede esta mudança com relação à concepção tradicional de ensino.

Em contraposição, não são novas as recomendações para que o professor considere o aluno um aprendiz ativo, podendo ser encontrado atualmente um número significativo de pesquisas sobre o aluno participativo e reflexivo (SOUZA, VIEIRA, MELO, 2016; MORENO, VELÁSQUEZ, 2017; KORFF et al., 2016), que interage com colegas e com o saber a ser assimilado, que leve em conta as dificuldades e obstáculos como momentos para intervenção do professor (MOREIRA, 2010). Este objetivo é sustentado em distintas estratégias de ensino, não somente em casos em que os alunos manipulam aparatos experimentais. Maestrelli e Lorenzetti (2017), por exemplo, sugere trabalhos que se utilizam do enfoque CTS (Ciência, Tecnologia e Sociedade):

... o enfoque CTS funciona como uma força cultural que é capaz de
induzir à participação mais ativa de todos os cidadãos contribuindo para
uma sociedade de melhor qualidade democrática, onde o caminho da
mudança e do progresso passa por um modelo misto de princípios e
ações. (MAESTRELLI, LORENZETTI, 2017, p.6)

Esse panorama da Educação Escolar não parece estar limitado a um particular país, sendo possível encontrar em pesquisas internacionais resultados semelhantes aos aqui divulgados pelas revistas e congressos da área. Por exemplo, Franklin, Sayre e Clark (2014) mostram que a aprendizagem que decorre de aulas expositivas tradicionais não é sustentada mais do que quatro semanas após o ensino. Ao contrário, um ensino onde o próprio aluno é protagonista deste processo promove aprendizagem mais duradoura. Mas pesquisas como esta parecem ser ainda insuficientes para que aconteçam mudanças nas práticas de professores.

A esse respeito, algumas reflexões são pertinentes. Pesquisas apontam que a incorporação de uma tradição de ensinar se inicia antes dos cursos de formação inicial docente, enquanto o pretendente a professor se encontra ainda na condição de aluno do ensino básico, portanto, sendo influenciada desde o EB até o Ensino Universitário (CATANI, BUENO, SOUZA, 2000; SILVA, CARVALHO, 2009; QUADROS et al., 2005).

O que parece acontecer é que ex-professores, por meio de suas práticas e pensamentos, exercem forte influência na formação do futuro professor (GIL-PÉREZ, 
CARVALHO, 1994; PÉREZ GÓMEZ, 1995). Neste sentido, Quadros et al. (2010), ao analisar os resultados de uma pesquisa empírica por eles realizada "mostra que professores podem influenciar muito mais pelo exemplo, pela postura e pelo tipo de aula que ministram do que as próprias teorias que tratam do 'ensinar e aprender'" (p.307).

Da mesma forma, Delizoicov (2005, p.372) afirma que "o professor formador desempenha papel exemplar para a atuação docente, tanto ao adotar práticas consistentes com os resultados de pesquisa como ao manter práticas tradicionais de ensino". Para Menezes e Vaz (2009), "diferentemente de outras profissões, o professor começa a interagir com o seu campo de trabalho desde muito cedo, quando do seu ingresso nas séries iniciais de sua formação escolar" (p.2). Para estes autores, a força do ambiente e das práticas vivenciadas faz com que os indivíduos reproduzam tanto ambiente como práticas em trabalhos futuros, impedindo uma crítica mais aguda e o abandono de crenças construídas, o que remete a um comportamento acadêmico e escolar institucionalizado (YAMAZAKI, 2015, p.21).

Novamente, essas inferências não são restritas ao Brasil. É o que mostram Van Eijck, Hsu e Roth (2009) para os quais estudantes adquirem disposições didático-pedagógicas, epistemológicas e ontológicas em vivências particulares de sala de aula. Perrenoud (1999) aponta um currículo oculto formador de esquemas de percepção, de avaliação, de pensamento e de ação. No entanto, tais esquemas nem sempre são percebidos pelos próprios professores, dificultando sua problematização. As atividades efetuadas no dia a dia de forma mecanizada e irrefletida obstaculizam a identificação de questões e condutas e, além disso, a dificuldade aumenta na medida em que essas práticas são condutas evidentemente institucionalizadas.

Diante do cenário monótono e persistente, sustentamos que uma reorientação didático-pedagógica exige dos professores mais do que aprendizagem de teorias e métodos para serem utilizados em sala de aula, mas mudanças em hábitos adquiridos durante toda a vida escolar, de modo que eles devem aprender a ensinar de uma forma "que eles mesmos não foram ensinados" (MENEZES, VAZ, 2009, p.5).

Trata-se, portanto, de um desafio a nós pesquisadores e professores, em projetos que envolvam a participação de escolas e universidades. Contudo, há elementos que se analisados criticamente, parecem apontar para manutenção dos pressupostos e práticas de ensino, demonstrando certo grau de influência na formação de concepções futuras. Entre estes, o livro didático ou manual de ensino parece ser um elemento privilegiado, pois seu uso cotidiano faz com que o mesmo seja um material fundamental para a aprendizagem de saberes escolares.

O manual é considerado por muitos professores e pesquisadores como um dos principais veículos formadores de práticas e teorizações sobre o ensino (MARPICA, LOGAREZZI, 2010; ARAÚJO NETO, SANTOS, 2001; MEGID NETO, 2011), sendo muitas vezes fonte única de conhecimentos para os aprendizes (DELIZOICOV, ANGOTTI, PERNAMBUCO, 2002; ROSA, SILVA, 2010; LOBATO ET AL, 2009; TAVARES, 2009; LANGUI, NARDI, 2007).

Além disso, outros (AMARAL, XAVIER, MACIEL, 2009; ROSA, MOHR, 2010; CARNEIRO, SANTOS, MÓL, 2005) distinguem o manual como recurso mais empregado pelos professores para elaboração de atividades didáticas, o que leva a ideia de que ele dissemina um consenso disciplinar (SOUZA, PORTO, 2009).

Trabalhando especificamente com a área de Física, Hosoume et al. (2011) mostram que nos últimos cinco anos que antecedem 2011, havia meia centena de dissertações e teses que 
tinham como objeto de pesquisa o livro didático de Física, mostrando sua importância como elemento que legitima práticas científicas e escolares, e levando à congruência com o que Milicic et al. (2007, p.282) afirmam:

Finalmente e como crença destacada, o saber-a-ensinar é a Física que está contida nos manuais internacionais de amplo uso e tradição. A alta coincidência em conteúdos destes manuais indica que a Física básica é concebida como uma entidade "única", o que coincide com uma ideia convergente e doutrinal da atividade docente, expressa nas concepções profissionais.

Com esta perspectiva, temos como pressuposto a hipótese de que o manual de Física é um potencial instrumento formador de concepções e práticas sobre o saber escolar, e sobre seu ensino, motivo que nos levou a esta pesquisa. Portanto, tendo o manual de Física como nosso objeto de investigação, procuramos analisá-lo com o objetivo de verificar se o estudo do mesmo pode levar estudantes e professores a algumas das concepções didáticopedagógicas e epistemológicas espontâneas divulgadas há algum tempo na literatura da área.

Especificamente, procuramos responder às questões: a forma com que a Física é apresentada nos manuais tem alguma correlação com as concepções alternativas dos professores encontradas na literatura da área? É possível que o manual de Física seja um criador ou reforçador destas concepções?

\section{Método de pesquisa}

Para responder às nossas questões, fizemos um levantamento dos manuais de Física mais citados nos Projetos Político-Pedagógicos (PPPs) de universidades brasileiras e de algumas do exterior com o objetivo de selecioná-los como objetos de pesquisa. Os PPPs selecionados foram todos os encontrados nos sites de cursos de graduação em Física, onde constavam os manuais de Física, a saber, nas bibliografias das disciplinas que constituíam os cursos.

O levantamento dos manuais contidos nas bibliografias das disciplinas dos PPPs permitiu verificar a existência ou inexistência de obras que se constituíssem como referências de um saber a ensinar inerente aos cursos de formação inicial de professores de física.

Procuramos verificar as bibliografias de disciplinas do ciclo básico dos cursos de Física, pois estas são as referências fundamentais para o desenvolvimento de atividades da docência e também para aprofundamento de concepções e estudos específicos que compõem o campo da Física. Neste sentido, mesmo em disciplinas mais avançadas, em se tratando do ensino de Física, os manuais do ciclo básico apresentam os fundamentos básicos a partir dos quais formalismos matemáticos e conceituais podem ser aprofundados.

Os manuais foram classificados em bibliografia básica e bibliografia complementar, conforme constam nos PPPs. Para considerar um manual significativo, adotamos o seguinte critério: um manual deveria ser citado em mais de uma disciplina na bibliografia básica.

Os manuais significativos foram colocados em tabelas e gráficos para melhor visualização. Analisamos o manual mais citado, pois este deve ser considerado exemplar significativo a ser seguido pelos professores e alunos de Física. 
Após a identificação desses manuais, a análise de sua estrutura e dinâmica foi feita utilizando-se da praxeologia de Yves Chevallard, proposta contida em sua Teoria Antropológica do Didático (TAD). A transformação dos dados brutos - contidos no texto do manual analisado - em elementos da TAD obedeceu à verificação de situações que pareciam ter semelhanças com a estrutura didática chevallardiana. Portanto, foram feitas aproximações entre as noções caracterizadas pela TAD - técnica, tecnologia e teoria, apresentadas no tópico a seguir -, e os dados brutos que levaram aos resultados finais da pesquisa. Nesse sentido, as noções da TAD, utilizadas para categorizar os dados desta pesquisa, se constituíram como categorias efetivamente significativas a partir das quais foram feitas as inferências didático-pedagógicas (PACCA, VILLANI, 1990).

\section{Teoria antropológica do didático}

A noção de praxeologia na obra chevallardiana explica e formaliza as práticas dentro de certas instituições e é encontrada em sua Teoria Antropológica do Didático (TAD). Para a $T A D$, as praxeologias são reproduzidas pelas instituições por meio de ações comuns muitas vezes inconscientes ao grupo (CHEVALLARD, BOSCH, GASCÓN, 2001).

O termo instituição se refere a coletivos de indivíduos que compartilham dos mesmos hábitos, "da mesma rotina, ou seja, comungam das mesmas organizações praxeológicas" (ZANARDI, KNEUBIL, PEREIRA, 2013, p.605). Chevallard (sem data) utiliza o termo praxeologia para identificar um postulado antropológico geral que compreende as atividades humanas regulares como ações prescritas por um modelo único que descreve e caracteriza as distintas áreas acadêmicas.

Portanto, a praxeologia é o estudo das ações e dos pensamentos dos indivíduos e "inclui não somente o que as pessoas fazem e como fazem, mas também o que pensam e como pensam" (YAMAZAKI, 2015, p.73). Segundo Chevallard (2005), uma didática específica requer uma praxeologia específica, ou seja, uma descrição e uma análise do que fazemos e pensamos em certos círculos particulares. Tal raciocínio remete a modelos institucionalizados que caracterizam fortemente distintos campos acadêmicos.

Sendo assim, discursos podem ser racionais para uma área e não ser para outra, como Chevallard (1999, p.4) afirma: "... uma racionalidade institucionalmente dada poderá aparecer... como pouco racional em outra instituição".

Para Chevallard (1999), a praxeologia analisa as atividades de membros de uma área pela caracterização do que denominou de tipos de tarefa. Os tipos de tarefa são realizações de atividades que são específicas de uma determinada área. Assim, calcular a aceleração média seria um exemplo de tipo de tarefa, sendo o verbo calcular sem o complemento aceleração média, um gênero de tarefa. Chevallard (1999) exemplifica usando-se de outro verbo: enquanto subir é um gênero de tarefa, subir a escada é um tipo de tarefa.

Mas como resolver o tipo ou gênero de tarefa? Utilizando-se de técnicas, de maneiras de fazer (CHEVALLARD, BOSCH, GASCÓN, 2001). Os tipos de tarefa e as técnicas para resolvê-los são denominados de bloco prático-técnico ou saber-fazer.

Por trás do bloco prático-técnico existe um discurso racional que o sustenta, um logos, como afirmam os autores a seguir: 
$\mathrm{Na}$ atividade matemática, como em qualquer outra atividade, existem duas partes, que não podem viver uma sem a outra. De um lado estão as tarefas e as técnicas [bloco prático-técnico ou saber-fazer] e, de outro, as tecnologias e as teorias [bloco tecnológico-teórico ou saber]. A primeira parte é o que podemos chamar de "prática" ou, em grego, práxis. A segunda é composta de elementos que permitem justificar e entender o que é feito, é o âmbito do discurso fundamentado (...) sobre a prática, que os gregos chamaram de logos. (...). Quando juntamos as palavras gregas práxis e logos, dá a palavra praxeologia. (CHEVALLARD, BOSCH, GASCÓN, 2001, p.251)

Em outros termos, como tecnologia compreende-se um discurso racional que justifica a técnica empregada para resolver os tipos ou gêneros de tarefas; e como teoria compreende-se, por sua vez, um discurso racional capaz de justificar a tecnologia. A teoria, portanto, é um nível superior de justificativa para a técnica empregada. Dessa forma, a descrição completa (ou "praxeologia completa") é representada pelos três níveis: técnica/tecnologia/teoria.

Assim, para responder a uma questão, "é necessário elaborar uma praxeologia (...) constituída por um tipo de problema determinado, uma ou várias técnicas, sua tecnologia e a teoria correspondente" (CHEVALLARD, BOCH, GASCÓN, 2001, p.275). Nesse sentido, a praxeologia permite descrever a tradição ensino de Física em parte registrada nos manuais da área, ao fornecer elementos que atribuem características à realização das tarefas apresentadas.

Ao verificar os tipos ou gêneros de tarefas presentes nos manuais de Física, as técnicas utilizadas para resolvê-los, e as tecnologias e teorias que as justificam, podemos visualizar a estrutura que mantém a tradição ensino de Física, permitindo responder às questões de pesquisa.

\section{Resultados}

\begin{tabular}{|c|c|c|c|}
\hline $\begin{array}{c}\text { Autores das Obras } \\
\text { do Ciclo Básico }\end{array}$ & $\begin{array}{c}\text { Porcentagem } \\
\text { encontrada como } \\
\text { Bibliografia Básica }\end{array}$ & $\begin{array}{c}\text { Porcentagem encontrada } \\
\text { como Bibliografia } \\
\text { Complementar }\end{array}$ & $\begin{array}{c}\text { Soma das } \\
\text { Porcentagens (Básica } \\
\text { mais Complementar) }\end{array}$ \\
\hline Alonso & 6,6 & 19,8 & 26,4 \\
\hline Chaves & 11 & 16,5 & 27,5 \\
\hline Feynman & 2,2 & 17,6 & 19,8 \\
\hline Halliday & 81,3 & 15,4 & 96,7 \\
\hline Nussenzveig & 37,4 & 21 & 58,4 \\
\hline Serway & 16,5 & 16,5 & 33 \\
\hline Tipler & 57,1 & 16,5 & 73,6 \\
\hline Young (Sears) & 33 & 26,4 & 59,4 \\
\hline
\end{tabular}

Tabela 1: Porcentagem de manuais encontrados em projetos político-pedagógicos em bibliografias de disciplinas do ciclo básico

As bibliografias de disciplinas levantadas foram encontradas em projetos políticopedagógicos de cursos de Física de 22 universidades, sendo 19 delas do Brasil e 3 do exterior. Analisamos 91 disciplinas que pertenciam ao ciclo básico de Física, as conhecidas por Física Geral 1 a 4. 
Dos 65 manuais encontrados, muitos não eram significativos com relação à praxeologia, não atendendo ao critério de serem citados em mais de uma disciplina na bibliografia básica. Somente 8 manuais atenderam a este critério e estão especificados na tabela 1 e gráfico 1 :

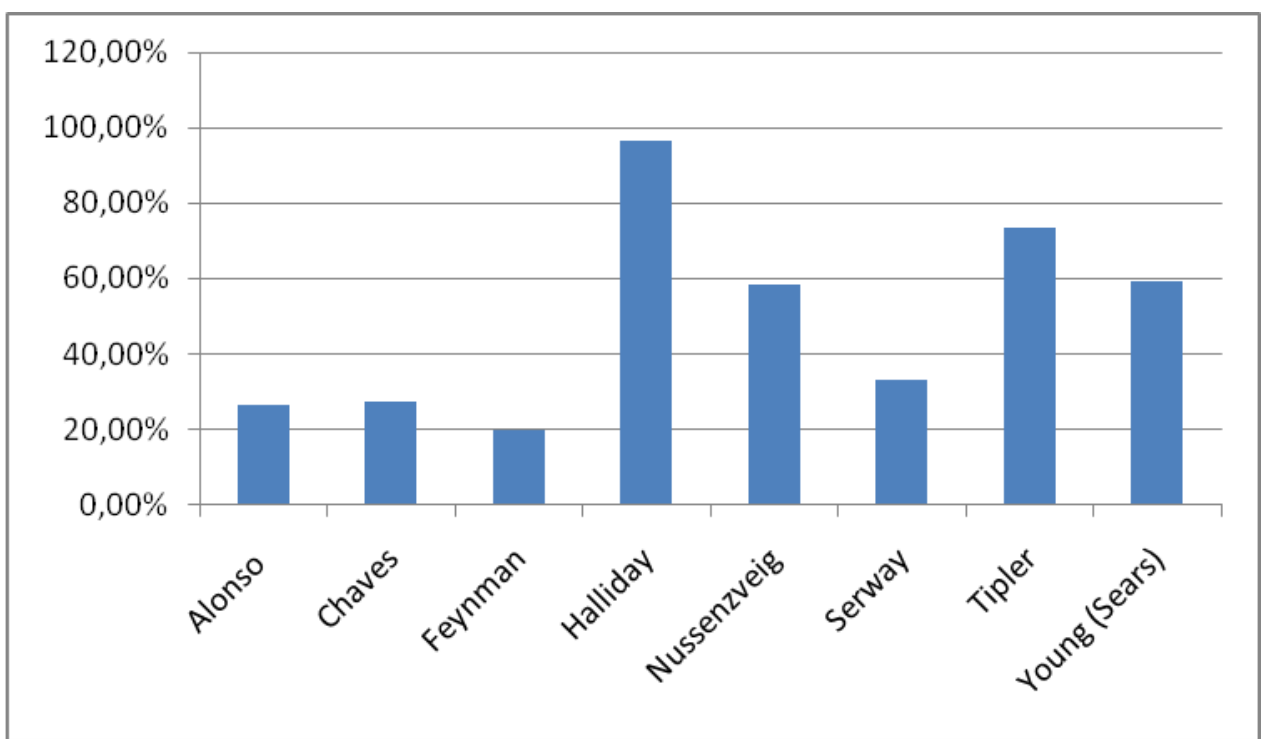

Figura 2 - Gráfico referente à porcentagem de manuais citadas em bibliografias básica e/ou complementar de disciplinas do ciclo do ciclo básico encontrados nos projetos político-pedagógicos dos cursos de graduação em Física

O gráfico mostra que o manual mais citado é o do autor Halliday e, portanto, este foi nosso objeto de pesquisa. Foram analisados 14 capítulos dos manuais deste autor, por meio da leitura do original (em inglês) - Fundamentals of Physics, 9th ed., 2011, volume único - e do manual traduzido para a língua portuguesa (versão brasileira) em 2012, em 4 volumes. A análise da versão nacional e da versão original foi proposital, para que pudéssemos verificar se havia diferenças quanto a praxeologia empregada. Percebemos que não havia diferença qualitativa entre elas. Portanto, faremos referência neste trabalho somente à versão brasileira da obra.

Procuramos considerar a totalidade de conteúdos de Física para avaliação praxeológica, buscando levantar uma didática inerente a tradição de como ensinar a Física. Entretanto, para esse objetivo, não é necessária a análise de todos os capítulos do manual escolhido, uma vez que os distintos temas/conteúdos sejam contemplados: mecânica, termologia, eletricidade e magnetismo, gravitação, física quântica e relatividade.

Os capítulos selecionados foram os seguintes: 2 (Movimento Retilíneo) , 4 (Movimento em Duas e Três Dimensões) , 5 (Força e Movimento I), 6 (Força e Movimento II), 7 (Energia Cinética e Trabalho), 8 (Energia Potencial e Conservação da Energia)e 9 (Centro de Massa e Momento Linear), 13 (Gravitação), 16 (Ondas), 18 (Termologia, Calor e Primeira Lei da Termodinâmica), 22 (Campos Elétricos), 28 (Campos Magnéticos), 37 (Relatividade) e 38 (Fótons e Ondas de Matéria). 


\section{Como os temas/conteúdos de física são apresentados nos manuais?}

Identificamos 3 tipos de gêneros de tarefa, os quais definimos pelos verbos: calcular, determinar e estudar. O gênero calcular é encontrado quando a resolução da tarefa requer apenas o uso de equações. O gênero determinar é encontrado quando, além da equação, a resolução da tarefa requer o uso de definições, enunciados, princípios. E, por último, o gênero estudar é encontrado quando a resolução da tarefa não solicita o uso de equações.

Pelo fato desta classificação apontar para aspectos que se inter-relacionam (pois o uso de equações carrega certas noções teóricas e definições; e os estudos levam a equações), não foi possível mostrar as porcentagens exatas de cada gênero de tarefa, mas é evidente que o gênero de tarefa calcular é predominante em todo o manual. Sendo assim, a tarefa fundamental encontrada nos manuais é a que solicita resolução de certas situações e problemas por meio de equações.

A partir da análise praxeológica é possível levantar que 87,7\% das tarefas encontradas na apresentação do conteúdo e $90 \%$ dos exemplos - os problemas resolvidos - promovem cálculos sob a fundamentação de definições feitas por meio de equações matemáticas. Estas, portanto, se constituem como as técnicas para resolver os gêneros/tipos de tarefas, tanto no que se refere à apresentação do conteúdo quanto na exemplificação de como resolver determinadas situações particulares, cotidianas ou práticas.

Nesse sentido, ao aprender uma técnica de resolução de um tipo/gênero de tarefa, o indivíduo sempre que se deparar com este tipo de tarefa, utiliza-se desta técnica tal como um algoritmo é colocado para funcionar e gerar uma resposta (YAMAZAKI, 2015). Como exemplo, a Segunda Lei de Newton, é apresentada também como técnica para resolver tipos de tarefas. Em seguida, um problema resolvido mostra como utilizá-la: a equação é posta para funcionar e gerar respostas, tal como um algoritmo.

Há no manual outros exemplos que apontam para esta forma de ensinar, o que pode levar até o momento da análise à formação de duas concepções: a de que a Física é predominantemente uma ciência que visa responder a questões práticas do dia a dia e também que é fundamentalmente um conglomerado de equações definidas pelos cientistas.

Além do uso de equações para resolver tipos de tarefa, os autores do manual também apresentam soluções por meio de gráficos. Em 18,4\% dos tópicos analisados e em 31,2\% dos problemas resolvidos, gráficos são utilizados para apontar como resolver certos tipos de tarefa. Um exemplo do uso de gráficos como técnicas para resolução de tipos de tarefa pode ser dado pela "determinação da velocidade por integração", onde um gráfico é construído para mostrar que através da área podemos obter a resposta a esta tarefa.

Outra técnica para resolver tipos/gêneros de tarefa encontrada nos manuais é aquela feita pelo uso de definições, regras ou enunciados, sem necessidade de equações ou gráficos. Este tipo de técnica é encontrado em 32,4\% do texto e em 25,3\% dos problemas resolvidos. A Primeira Lei de Newton é um exemplo deste tipo de técnica para resolver tarefas, pois seu enunciado é suficiente para responder uma série de questões. Também a Terceira Lei de Newton é um exemplo deste tipo de técnica para achar soluções de tipos de tarefa. Assim, ao apresentar questões como movimento de blocos pendentes em um fio, essa lei pode responder a várias perguntas desse processo. Outros exemplos poderiam ser dados (estudo das ondas, princípio da equivalência), mas nosso objetivo não é exemplificar 
de forma exaustiva esses aspectos referentes ao manual, mas de mostrar como efetivamente eles existem na apresentação de seu conteúdo.

É imperativo observar que as porcentagens com relação à caracterização das técnicas encontradas nos textos não são excludentes, pois muitas vezes um desenvolvimento teórico possui mais do que uma categorização. Por exemplo, um desenvolvimento que leva a uma determinada equação pode também contemplar o processo pelo uso de gráficos (outra categoria), ou ainda, pelo uso de leis ou enunciados que não se utilizam de matematizações. Dessa forma, a soma das porcentagens com relação aos textos analisados ultrapassam os 100\%. E isso acontece também com relação aos problemas resolvidos pelos mesmos motivos.

Procuramos também mostrar de que forma as técnicas empregadas para resolver os tipos/gêneros de tarefas são sustentadas ou justificadas pelos autores dos manuais. Em termos chevallardianos, a questão é: que tecnologias são encontradas nesses manuais?

Classificamos as tecnologias em definições, descrições, deduções lógicas e contextualização histórica. Uma definição é caracterizada por não conter um discurso prévio que justifique a origem da técnica, seja na forma puramente conceitual ou matemática. Ou seja, não é possível entender as razões que levaram os cientistas a tal técnica, sendo necessário aceita-la acriticamente. A tecnologia definição está presente no manual em 55,9\% dos casos.

Uma descrição é a tecnologia que se funda em discursos prévios, que tentam dar plausibilidade à técnica devido a referência a determinadas situações. É o caso de situações que exploram o cotidiano para levar a elaboração de uma técnica/equação. A tecnologia descrição está presente no manual em 42,5\% dos casos.

As deduções lógicas são tecnologias que tornam racionais as técnicas utilizadas ao mostrar que estas tiveram origem em conceitos, definições ou equações anteriores. Por exemplo, duas equações já definidas que, quando manipuladas, dão origem a uma terceira equação, esta tendo origem, portanto, em uma dedução lógica. Então, neste caso, a origem da técnica representada por esta terceira equação pode ser compreendida. Por exemplo, no capítulo 7 do manual duas equações são manipuladas, a segunda lei de Newton (técnica cuja tecnologia é uma definição) e uma equação para velocidade com aceleração constante, com o objetivo de obter uma outra equação: a equação do Trabalho realizado por uma Força. A equação deduzida (do trabalho) pode ser utilizada como uma técnica para resolver tipos de tarefas, e sua tecnologia é do tipo dedução lógica, pois é possível entender que foi gerada de outros elementos da Física. A tecnologia dedução lógica está presente no manual em 38\% dos casos.

Por último, a contextualização histórica é a justificativa que mostra a que problemas e propósitos a técnica era destinada. Nesse caso, é possível compreender as origens da técnica utilizada podendo levar à plausibilidade da mesma. A tecnologia contextualização histórica está presente em apenas 0,6\% dos casos.

O último nível de justificativa na praxeologia de Chevallard - a teoria - teria como objetivo a promoção de um discurso sobre as tecnologias para que estas não tenham um caráter arbitrário. Mas no manual de Física não há discursos sobre a história e seu contexto referentes às definições ou enunciados (as tecnologias) que justificam as técnicas. Sendo assim, as técnicas são justificadas pelas tecnologias, mas estas não são justificadas, levando a um grau mais elevado de possível arbitrariedade. 


\section{Inferências: fenômenos didáticos}

A literatura da área tem apontado já há algum tempo que estudantes e professores possuem concepções sobre a ciência e o cientista que não se afinam com a epistemologia contemporânea (GIL-PÉREZ et al, 2001). Em se tratando da gênese do conhecimento, os estudantes de ensino médio e universitário mostram concepções ora empiristas, ora racionalistas (ARCANJO FILHO et al., 2009), assim como a "grande maioria dos professores" (GOMES, BELLINI, 2009; BECKER, 2012; BECKER, 1993).

A análise praxeológica do manual mostra que este material didático pode estar proporcionando a formação dessas concepções ou reforçando-as. Nos momentos em que definições, leis ou enunciados, são apresentados como tecnologias que justificam certas técnicas sem prévias discussões que as contextualizam e dão a elas plausibilidade, vários sentidos podem ser atribuídos a essa prática.

Um dos sentidos que pode se sobressair dessa didática encontrada nos manuais de Física é de que os elementos que sustentam essa Ciência (as definições, enunciados etc. tecnologia definição) têm origem em mentes de cientistas brilhantes (tal como mostram outras pesquisas, por exemplo, Rodrigues, Yamazaki, 2009; Souza, Araújo, 2007; Omena, Silva, Cavalari, 2011; Lara et al., 2013; Ribeiro, Martins, 2007) e, portanto, não há necessidade de apresentar o contexto e sua história que levem a sua plausibilidade e aceitação lógica. Do ponto de vista epistemológico, este cenário pode levar à compreensão de que a atividade do físico é essencialmente caracterizada pela lógica racionalista (HESSEN, 2000), concepção apontada em algumas pesquisas (ARCANJO-FILHO et al., 2009).

Porém, em outros momentos da apresentação da Física nestes manuais, as observações cotidianas sustentam as leis ou definições (tecnologia descrição), podendo levar à compreensão de que as experiências e observações que dão origem à Física. Epistemologicamente, esta ênfase didática parece apontar para formação de uma concepção empirista (HESSEN, 2000).

A dicotomização da atividade do cientista está presente também no meio acadêmico, afinal, muitas vezes o próprio cientista não tem consciência de seus passos para executar suas tarefas, pois foram sendo incorporadas em um processo contínuo de mecanização. Com relação a este ponto, Gomes e Bellini (2009) afirmam: "não se iluda o leitor de que a visão empirista-racionalista esteja ausente do meio científico (...). Vários estudos têm demonstrado que a visão epistemológica da grande maioria dos professores é empirista ou racionalista" (p. 8), contrariando a concepção da epistemologia contemporânea de que o conhecimento é formado por meio da interação entre ambos, sujeito e objeto.

As duas caracterizações epistemológicas com relação à origem do conhecimento que podem estar formalizando práticas científicas, seriam amenizadas ou evitadas se fossem apresentadas em um contexto de discussão mais amplo, onde além da lógica interna das teorias em questão, os motivos reais, movidos por interesses externos, também fossem destacados nos textos (CARVALHO, SASSERON, 2010).

Além disso, mesmo que fossem reduzidas à lógica interna da teoria, o entendimento das mesmas é dificultada quando as questões de âmbito subjetivo não são discutidas ou apresentadas, tal como afirma Hessen (2000):

Assim, se o racionalismo deriva tudo do pensamento e o empirismo deriva tudo da experiência, devemos contrapor a ambos os resultados da psicologia que apontam para uma mescla de conteúdos intuitivos e não- 
intuitivos na consciência, para uma atuação conjunta de fatores racionais e empíricos no conhecimento humano. (HESSEN, 2000, p.47)

Outras consequências podem estar surgindo a partir da caracterização do manual de Física analisado. A apresentação dos pressupostos da Física sem contextualização histórica também pode estar levando à compreensão de que a Física é elaborada de forma dogmática, entrando em consonância com a literatura da área (por exemplo, PINHO ALVES, 2000; ASSIS E TEIXEIRA, 2003). À concepção dogmatista somam-se outros pressupostos, também já apontados pela literatura, que podem estar surgindo ou sendo alimentados nos manuais de Física: (1) a ideia de que a "Física é uma obra acabada" (FIOLHAIS, 2005), (2) a ideia de que "não existem questões iniciais para as quais os cientistas buscam soluções" (CAMARGO, NARDI, 2003), e (3) a ideia de que "sem equações ou matematizações não há física" (ZAN et al, sem data).

A primeira dessas ideias (1) é sustentada nos manuais ao não permitir uma discussão sobre o processo histórico que levou aos conceitos e pressupostos da Física atual, expondo somente o que é sustentado hoje por essa ciência. Esse caminho didático não permite a compreensão de que as teorias são resultado de um processo permeado por discussões e interesses internos e externos à própria ciência.

A falta de discussão sobre o contexto que levou os cientistas a elaborarem conjecturas e tentativas de solução também aponta para visão de que na origem do conhecimento não há necessidade de uma problematização, ou seja, de que (2) "não existem questões iniciais", concepção espontânea que a literatura vem apontando.

Outro ponto (3) didático articulado no manual, sobre os tipos de tarefas e as técnicas utilizadas para resolvê-los - preponderantemente por meio de equações - sustenta a concepção espontânea encontrada nos resultados de investigações que denotam à Física um empreendimento matemático. Ricardo e Freire (2007), por exemplo, mostram em pesquisa empírica que apenas 35,5\% dos alunos da Educação Básica que participaram do levantamento, tinham a compreensão de que Física não era Matemática. Sobre esse resultado, os autores afirmam:

Embora seja indispensável a habilidade matemática na física, não é a única e, tampouco, esta se reduz àquela. Assim, verifica-se que esses alunos tiveram acesso a um ensino de física excessivamente preso à matematização e à aplicação de fórmulas. (RICARDO, FREIRE, 2007, p.253)

Outra possível inferência que resulta de nossas análises também é encontrada na literatura da área. Refere-se à concepção pragmatista segundo a qual a ciência deve ter eminentemente utilidade cotidiana, concebendo-a como um "princípio de explicação" (ANDRADE, ZYLBERSZTAJN, FERRARI, 2002). O caráter utilitarista e pragmático, que reveste a ciência, está implicitamente presente no ensino das disciplinas (SENICIATO, SILVA, CAVASSAN, 2006), e também no manual de Física analisado, aspecto que pode estar levando os estudantes e professores a pensarem esta ciência dessa forma.

Ao introduzir os capítulos por meio de referências ao cotidiano ou à aplicação tecnológica, sem problematizações e nem contextualização histórica, os manuais apresentam um cenário como princípio explicativo para o desenvolvimento da Física, parecendo justificar sua relevância. Esta dinâmica no ensino da Física presente nos manuais, que parte de fenômenos do dia a dia e de sua relação direta com os princípios científicos 
(físicos), não leva a reflexão e problematização dos pressupostos espontâneos sobre estes fenômenos, afinal a Física não é uma extensão acrítica do senso comum (PATY, 2003).

Por conseguinte, Andrade, Zylbersztajn e Ferrari (2002, p. 6) afirmam: "há uma grande ruptura entre o conhecimento científico e o conhecimento comum"; e "enquanto o conhecimento vulgar permanece ligado a princípios empiristas de generalidade, de utilidade, de finalismo, o conhecimento científico está cada vez mais ligado a princípios racionais, é cada vez mais teórico".

Todos os sentidos supracitados, atribuídos à leitura do manual, denotam implicações originadas em uma estratégia de ensino de Física. São, portanto, resultantes de certas perspectivas relacionadas à Física que denominamos de fenômenos didáticos. Os fenômenos didáticos seriam fatos empíricos, "regularidades que surgem através do estudo de problemas de pesquisa" (ARTIGUE, BOCH, GASCÓN, sem data, p. 3). Trazendo para as questões didáticas, "analogicamente, a dinâmica das praxeologias didáticas de um conhecimento específico acaba determinando certos comportamentos peculiares externalizados como fenômenos didáticos" (YAMAZAKI, 2015, p.75).

De forma pontual,

Definimos como fenômenos didáticos todas as concepções formadas pelos estudantes em função das características didáticas existentes nas estratégias de ensino adotadas. Chevallard, Bosch e Gascón (2001) apontam para muitas incompreensões de estudantes com relação ao conteúdo de matemática que muitas vezes são explicadas por consideração de aspectos externos às especificidades da disciplina, envolvendo questões de ordem social, psicológica ou pedagógica; no entanto, eles sugerem que estas incompreensões são resultado de uma didatização que não considerou o estudo da estrutura da própria disciplina. (YAMAZAKI, 2015, p.130)

Dessa forma, sendo o manual de Física o recurso mais precioso do processo de formação docente, os fenômenos didáticos que dele podem se sobressair problematizam a estrutura e a dinâmica utilizadas para apresentação do conteúdo.

Os fenômenos didáticos são concepções incorporadas pela didática do manual, reproduzida pelos professores, e sustentadas pela mecanização de uma leitura pedagógica acrítica; essas concepções acabam sendo concebidas como elementos que instrumentalizam o ensino da disciplina, se constituindo como um espírito didático para o ensino de Física. (YAMAZAKI, 2015, p.219)

Sendo assim, os fenômenos didáticos citados são congruentes com o que a literatura tem apontado com relação às concepções espontâneas de alunos e professores, e, portanto, podem ser decorrentes da didática presente no manual de Física analisado.

A didática presente no manual reproduz em todo texto as técnicas e tecnologias que podem estar levando aos fenômenos didáticos externalizados pelas investigações da área, sendo, portanto, uma estratégia de ensino que deve ser posta para discussão, reflexão e mudança.

Neste sentido, apontamos para a necessidade de outras propostas didáticas para os manuais de Física com objetivo de obter um panorama que leve a outras concepções didático-pedagógicas e epistemológicas tanto na formação quanto na prática de 
professores. Essa reflexão se faz necessária na medida em que as pesquisas não dialogam congruentemente com as práticas efetivas dos docentes, não permitindo que mudanças reais aconteçam.

\section{Considerações finais}

Os resultados dessa pesquisa são partes significativas de uma investigação maior que procurou verificar a didática presente em manuais de Física e de contrapor as análises com outros saberes de referência, considerados potencialmente mais promissores do ponto de vista da aprendizagem e da formação docente. Nossa intenção não é sugerir a supressão dos manuais na formação do professor de Física, mas a transformação de seu formato com relação a sua dinâmica e estrutura, no sentido de se adequarem às pesquisas da área dos últimos anos.

Outros manuais, além do apresentado (ver tabela - figura 1), foram pesquisados, porém de forma menos exaustiva. As análises apontam para resultados similares e, portanto, problematizam o que constitui uma didática tradicional do ensino de Física. Sendo os manuais analisados, traduções de obras do exterior (com uma exceção), os fenômenos didáticos podem estar caracterizando concepções de âmbito mundial, complexificando ainda mais o ensino da disciplina. Contudo, avanços são possíveis após a conscientização dos problemas internos do campo de estudo em questão.

Um dos problemas inerentes ao campo da Física refere-se à própria cultura que a sustenta como um saber disciplinar. Perfazem esta cultura os métodos de investigação e as normas e regras sobre como ensinar, constituindo-se ao todo como "critérios axiológicos (...) de atuação profissional e de modos de pensamento e de ação docente" (MILICIC, 2004, p.127), ou seja, como uma tradição do campo.

Este panorama é problemático na medida em que os resultados de pesquisas da área resultam em práticas individuais (DELIZOICOV, 2005) que, pelas características em que elas acontecem, não são capazes de questionar pontos "endêmicos" da tradição e nem de provocar alguma transformação no campo da educação científica. Nesse ponto, devemos investir no desdobramento da tradição corrente ao incorporar, nas reflexões e ações de atividades institucionalizadas, as implicações originadas em investigações da área.

Afinal, diferentemente da formação do físico, que tem como objeto de trabalho o estudo e a pesquisa de fenômenos naturais assentados em pressupostos ou modelos próprios de seu campo, o professor de física é direcionado a práticas que se se aproximam de outro objeto de trabalho, também fundamentalmente complexo, as práticas que lidam com processos didáticos que lidam especificamente com o ensino e aprendizagem dos modelos e pressupostos deste campo, portanto, indo além da compreensão dos próprios modelos a serem ensinados. Significa que a formação do professor de física caracteriza-se por uma formação no entorno de saberes e resultados em princípio epistemologicamente distantes, pois sustentam questões próprias de seu campo de atuação institucional.

Além disso, se o professor de física tem como objetivo central o ensino de física, o manual de física, sendo um formador em potencial de uma tradição ensino de Física, seria o aporte teórico por excelência que sustenta essa perspectiva, tendo como desafio a apresentação didática amparada em pesquisas da área.

No entanto, os manuais de física parecem estar refletindo as pesquisas que têm indicado que tentativas de mudanças com relação a questões didático-pedagógicas são 
inviabilizadas pelos próprios estabelecimentos oficiais em função da tendência à permanência de considerações habituais sobre a atividade de ensinar (AYDENIZ, HODGE, 2011), permitindo a formação de uma dicotomia entre a identidade do cientista e a identidade do professor (REZENDE, 2011).

Por outro lado, se a programação das disciplinas, durante a formação inicial do professor de física, não possibilitar articulações necessárias às perspectivas do professor do Ensino Médio, o profissional em atuação terá pela frente um problema a ser enfrentado para o qual não foi formado. Esse cenário, contudo, pode ser modificado se planejamentos coletivos entre aqueles que trabalham nesta interface da formação de futuros docentes levarem a inovações apoiadas em pesquisas que trazem inovações à área e estão materializadas em seus respectivos instrumentos de ensino, como indicam, por exemplo, as propostas didáticas viabilizadas pelas Tecnologias Digitais de Informação e Comunicação (TDIC), ao sugerir alternativas para o trabalho docente que se aproximam da realidade vivenciada pelo estudante nos dias atuais.

\section{Referências}

AMARAL, C. L. C.; XAVIER, E. S.; MACIEL, M. D. M. Abordagem das relações Ciência/Tecnologia/Sociedade nos conteúdos e funções orgânicas em livros didáticos de Química do ensino médio. Investigações em Ensino de Ciências, v.14, n.1, p.101-114, 2009.

ANDRADE, B. L.; ZYLBERSZTAJN, A.; FERRARI, N. As analogias e metáforas no ensino de ciências à luz da epistemologia de Gaston Bachelard. Ensaio - pesquisa em educação em ciências, v.2, n.2, p.1-11, 2002.

ARAÚJO NETO, W. N.; SANTOS, J. M. T. História da Química e sua apropriação pelo currículo escrito - a noção de valência nos livros didáticos de Química. Revista Brasileira de Pesquisa em Educação em Ciências, v.1, n.3, p.1-12, 2001.

ARCANJO-FILHO, M. et al. Uma pesquisa exploratória sobre questões epistemológicas no ensino das ciências. In: Encontro Nacional de Pesquisa em Educação em Ciências - ENPEC. Florianópolis, SC: Universidade Federal de Santa Catarina (UFSC), nov. 2009.

ASSIS, A.; TEIXEIRA, O. P. B. Algumas reflexões sobre a utilização de textos alternativos em aulas de Física. In: IV Encontro Nacional de Pesquisa em Educação em Ciências - ENPEC. Bauru, SP: 25 a 29 de Nov. 2003.

AYDENIZ, M.; HODGE, L. L. Is it dichotomy or tension: I am a scientist. No, wait! I am a teacher! Cultural Studies of Science Educational, v.6, p.165-179, 2011.

BECKER, F. Epistemologia do Professor de Matemática. Petrópolis, RJ: Vozes, 2012.

BECKER, F. Epistemologia do Professor: o cotidiano da escola. Petrópolis, RJ: Vozes, 1993.

CAMARGO, S., NARDI, R. Prática de ensino de Física: marcas de referenciais teóricos no discurso de licenciandos. In: IV Encontro Nacional de Pesquisa em Educação em Ciências. Bauru, SP: Universidade Estadual Paulista, 25 a 29 de nov 2003. 
CARNEIRO, M. H. S., SANTOS, W. L. P., \& MÓL, G. S. Livro Didático inovador e professores: uma tensão a ser vencida. Ensaio - Pesquisa em Educação em Ciência, v.7, n.2, p.1-13, 2005.

CARVALHO, A. M. P.; SASSERON, L. H. Abordagens histórico-filosóficas em sala de aula: questões e propostas. In: CARVALHO, A. M. P. et al (Orgs.). Ensino de Física. São Paulo: Cengage Learning, 2010. p.107-140.

CATANI, D. B.; BUENO, B. A. O.; SOUSA, C. P. O amor dos começos: por uma história das relações com a escola. Caderno de Pesquisa, v.111, p.151-171, 2000.

CHEVALLARD, Y. Steps towards a new epistemology in mathematics education. CERME, 4, p.21-30, 2005.

CHEVALLARD, Y.; BOSCH, M.; GASCÓN, J. Estudar Matemáticas: o elo perdido entre o ensino e a aprendizagem. Porto Alegre: Artmed, 2001.

CHEVALLARD, Y. El análisis de las prácticas docentes en la teoría antropológica de lo didáctico. Recherches en Didactique des Mathématiques, v.19, n.2, p.221-266, 1999.

CHEVALLARD, Y. (sem data). On didactic transposition theory: some introductory notes. In: http://yves.chevallard.free.fr/spip/spip/IMG/pdf/On_Didactic_Transposition_Theory.pdf.

Acessado em 10/05/2013.

CHINELLI, M. V.; FERREIRA, M. V. S.; AGUIAR, L. E. V. Epistemologia em sala de aula: a natureza da ciência e da atividade científica na prática profissional de professores de ciências. Ciência \& Educação, v.16, n.1, p.17-35, 2010.

DELIZOICOV, D. Resultados da pesquisa em ensino de ciências: comunicação ou extensão? Caderno Brasileiro de Ensino de Física, v.22, n.3, p.364-378, 2005.

DELIZOICOV, D.; ANGOTTI, J. A.; PERNAMBUCO, M. M. Ensino de Ciências: fundamentos e métodos. São Paulo: Cortez. 2002. 366p.

FIOLHAIS, C. Einstein e o prazer da Física: passados cem anos, a Física continua divertida. Física na Escola, v.6, n.1, p.11-14, 2005.

FRANKLIN, S. V.; SAYRE, E. C.; CLARK, J. W. Traditionally taught students learn; actively engaged students remember. American Journal of Physics, v.82, n.8, p.798-801, 2014.

GIL-PÉREZ, D.;CARVALHO, A. M. P. Formación del profesorado de las ciencias. Madri, Espanha: Editorial Popular, 1994.

GIL-PÉREZ, D. et al. Para uma imagem não deformada do trabalho científico. Ciência \& Educação, v.7, n.2, p.125-153, 2001.

GOMES, L. C.; BELLINI, L. M. Uma revisão sobre aspectos fundamentais da teoria de Piaget: possíveis implicações para o ensino de Física. Revista Brasileira de Ensino de Física, v.31, n.2, p.1-10, 2009.

HALLIDAY, D.; RESNICK, R.; WALKER, J. Fundamentals of Physics. 9ath. ed. United States of America: John Wiley\& Sons. 2011. 1247p.

HALLIDAY, D.; RESNICK, R.;WALKER, J. Fundamentos de Física, v. 1: mecânica. 9a ed. Rio de Janeiro: LTC. 2012. 372p.

HESSEN, J. Teoria do Conhecimento. São Paulo: Martins Fontes. 2000. 116p. 
HOSOUME, Y. et al. Um panorama das pesquisas em livros didáticos de física a partir dos resumos de teses e dissertações. In: XIII Encontro de Pesquisa em Ensino de Física - EPEF. Foz do Iguaçu, PR, de 05 a 10 de junho 2011.

KORFF, J. V. et al. Secondary analysis of teaching methods in introductory physics: A 50kstudent study. American Journal of Physics, v.84, n.12, p.969-974, 2016.

LANGUI, R.; NARDI, R. Ensino de Astronomia: erros conceituais mais comuns presentes em livros didáticos de Ciências. Caderno Brasileiro de Ensino de Física, v.24, n.1, p.87-111, 2007.

LARA, A. L. et al. Opiniões dos estudantes sobre o uso da história da ciência no ensino de Física: possíveis concepções e reflexões para um projeto de pesquisa. In: XX Simpósio Nacional de Ensino de Física - SNEF. São Paulo, SP: Universidade de São Paulo, 21 a 25 de jan. 2013.

LOBATO, A. C. et al. Dirigindo o olhar para o efeito estufa nos livros didáticos de ensino médio é simples entender esse fenômeno? Revista Ensaio, v.11, n.1, p.1-18, 2009.

MAESTRELLI, S. G.; LORENZETTI, L. As relações CTSA nos anos iniciais do Ensino Fundamental: analisando a produção acadêmica e os livros didáticos. Amazônia - Revista de Educação em Ciências e Matemáticas, v.13, n.26, p.05-21, 2017.

MARPICA, N. S.; LOGAREZZI, A. J. M. Um panorama das pesquisas sobre livro didático e educação ambiental. Ciência \& Educação, v.16, n.1, p.115-130, 2010.

MEGID NETO, J. O que mudou e o que ainda não mudou nos livros didáticos de física do ensino médio. In: XIII Encontro de Pesquisa em Ensino de Física - EPEF. Foz do Iguaçu, PR, de 05 a 10 de junho 2011.

MENEZES, P. H. D.; VAZ, A. M. Tradição e Inovação no Ensino de Física: a influência da formação e profissionalização docente. In: VII Encontro Nacional de Pesquisa em Educação em Ciências, Florianópolis, SC, de 08 a 13 de novembro de 2009.

MILICIC, B. et al.La cultura académica como condicionante del pensamiento y la acción de los profesores universitarios de física. Investigações em Ensino de Ciências, v.12, n.2, p.263284, 2007.

MILICIC, B. Tese (Doutorado - Facultad de Filosofía y Ciencias de la Educación). La cultura profesional como condicionante de la adaptación de los profesores de Física universitaria a la enseñanza de Física. 1700f. Valencia, Espanha: Universitat de Valencia, 2004.

MION, R. A.; ANGOTTI, J. A. P.; MIQUELIN, A. F. Estratégias didático-pedagógicas na formação de professores de física. In: IX Encontro Nacional de Pesquisa em Ensino de Física EPEF. Jaboticatubas, MG, de 26 a 30 de outubro 2004. p.1-12.

MOREIRA, M. A. Abandono da narrativa, ensino centrado no aluno e aprender a aprender criticamente. In: I/ Encontro Nacional de Ensino de Ciências da Saúde e do Ambiente, Niterói, RJ, 12 a 15 de maio de 2010; VI Encontro Internacional e III Encontro Nacional de Aprendizagem Significativa, São Paulo, SP, 26 a 30 de julho de 2010. p.1-12.

MORENO, J. A.; VELÁSQUEZ, N. Y. M. Enseñanza de las Leyes de Newton em grado décimo bajo la Metodología de Aprendizaje Activo. Amazônia - Revista de Educação em Ciências e Matemáticas, v.13, n.26, p.80-99, 2017. 
OMENA, B. S. S.; SILVA, L. F.; CAVALARI, M. F. Compreensão dos professores de Ciências sobre aspectos da Natureza da Ciência: algumas considerações sobre os docentes que atuam no ensino fundamental. In: VIII Encontro Nacional de Pesquisa em Educação em Ciências - ENPEC. Campinas, SP, 5 a 9 de dez 2011.

PACCA, J. L. A.; VILLANI, A. Categorias de Análise nas pesquisas sobre conceitos alternativos. Revista de Ensino de Física, v.12, p.123-138, dez. 1990.

PATY, M. A ciência e as idas e voltas do senso comum. Scientice Studia, v.1, n.1, p.9-26, 2003.

PERRENOUD, P. Construir as Competências Desde a Escola. Porto Alegre: Artmed, 1999. 96p.

PÉREZ GÓMEZ, A. O pensamento prático do professor: a formação do professor como profissional reflexivo. In: NÓVOA, A. (Org.). Os professores e sua formação. Lisboa, Portugal: Publicações Dom Quixote, 1995. p. 93-114.

PINHO ALVES FILHO, J. Regras da Transposição Didática aplicadas ao Laboratório Didático. Caderno Catarinense de Ensino de Física, v.17, n.2, p.44-58, 2000.

QUADROS, A L. et al. As práticas educativas e seus personagens na visão de estudantes recém-ingressados nos cursos de química e biologia. Ciência \& Educação, v.6, n.2, p.293308, 2010.

QUADROS, A. L. et al. Os professores que tivemos e a formação da nossa identidade como docentes: um encontro com a nossa memória. Ensaio - Pesquisa em Educação em Ciências, v.7, n.1, p.1-8, 2005.

REZENDE, F. Dynamics of identity in the academic field and implications to science student's identity formation. Cultural Studies of Science Education, v.6, p.187-192, 2011.

RIBEIRO, R. M. L.; MARTINS, I. O potencial das narrativas como recurso para o ensino de ciências: uma análise em livros didáticos de física. Ciência \& Educação, v.13, n.3, p.293-309, 2007.

RICARDO, EL. C.; FREIRE, J. C. A. A concepção dos alunos sobre a física do ensino médio: um estudo exploratório. Revista Brasileira de Ensino de Física, v.29, n.2, p.251-266, 2007.

RODRIGUES, P. G. S.; YAMAZAKI, S. C. Trabalhando a ideia de um cientista tendo como base a figura de Albert Einstein. In: XVIII Simpósio Nacional de Ensino de Física - SNEF. Vitória, ES: Universidade Federal do Espírito Santo (UFES), 26 a 30 de jan. 2009.

ROSA, M. D.; MOHR, A. Os fungos na escola: análise dos conteúdos de micologia em livros didáticos do Ensino Fundamental de Florianópolis. Experiências em Ensino de Ciências, v.5, n.3, p.95-102, 2010.

ROSA, S. R. G.; SILVA, M. R. A História da Ciência nos Livros Didáticos de Biologia do Ensino Médio: uma análise do conteúdo sobre o episódio da transformação bacteriana. ALEXANDRIA Revista de Educação em Ciência e Tecnologia, v.3, n.2, p.59-78, 2010.

SENICIATO, T.; SILVA, P. G. P.; CAVASSAN, O. Construindo valores estéticos nas aulas de ciências desenvolvidas em ambientes naturais. Ensaio - Pesquisa em Educação em Ciências, v.8, n.2, p.97-109, 2006. 
SILVA, L. F.; CARVALHO, L. M. Professores de Física em formação inicial: o ensino de física, a abordagem CTS e os temas controversos. Investigações em Ensino de Ciências, v.14, n.1, p.135-148, 2009.

SOUZA, A. H. S.; VIEIRA, R. D.; MELO, V. F. Atividades argumentativas em livros didáticos de Física do PNLD 2015: o incentivo ainda é escasso. Amazônia - Revista de Educação em Ciências e Matemáticas, v.13, n.25, p.100-115, 2016.

SOUZA, K. A. F. D.:PORTO, P. A. Educação Superior em Química entre texto e imagem: tendências de ensino a partir de livros didáticos de 1900 a 1939. In: VII Encontro Nacional de Pesquisa em Educação em Ciências - VII ENPEC. Florianópolis: UFSC, novembro de 2009. p.1-13.

SOUZA, R. O.; ARAÚJO, M. S. T. Intervenção visando a ressignificação de pré-concepções estudantis e estímulo ao engajamento às áreas científicas. In: VI Encontro Nacional de Pesquisa em Educação em Ciências - ENPEC. Florianópolis: Universidade Federal de Santa Catarina, nov. 2007.

TAVARES, L. H. W. Possibilidades de deformação conceitual nos livros didáticos de Química brasileiros: o conceito de substância. Revista Electrónica de Enseñanza de las Ciências, v.8, n.3, p. 1004-1018, 2009.

VAN EIJCK, M.; HSU, P.; ROTH, W. Translations of Scientific Practice to "Students' Images of Science". Science Education, v.93, n.4, p.611-634, 2009.

YAMAZAKI, S. C. Tese. 278f. Tradição do Ensino de Física em manuais de ensino superior. Programa de Pós-Graduação em Educação Científica e Tecnológica, Universidade Federal de Santa Catarina, 2015.

ZAN, R. et al. (sem data). Afffect in Mathematics Education: an introduction. Special Issue of Educational Studies in Mathematics. In: https://eprints.mdx.ac.uk/1701/1/EvansAFFECT_IN_MATHEMATICS_EDUCATION.pdf. Acessado em 11/11/2013.

ZANARDI, D. C.; KNEUBIL, F. B.; PEREIRA, V. S. Organização praxeológica de saberes escolares: uma comparação da equação de Clapeyron em livros de Física e Química. Investigações em Ensino de Ciências, v.18, n.3, p.601-620, 2013. 